\title{
Expression of a blood-brain barrier-specific antigen in the reproductive tract of the male rat
}

\author{
M. N. Ghabriel, J. J. Lu, G. Hermanis, C. Zhu* and B. P. Setchell \\ Department of Anatomical Sciences, Adelaide University, Adelaide 5005, South Australia
}

\begin{abstract}
The endothelial barrier antigen (EBA) is a protein expressed specifically by the endothelial cells of the rat brain barrier vessels. This antigen has been described as a 'barrier protein' and is used as a marker for the competent blood-brain barrier. A blood-testis barrier has also been described. However, unlike the blood-brain barrier, which is formed by endothelial cells, the blood-testis barrier is formed mainly by the Sertoli cells, which provide an isolated environment for spermatogenic cells within the seminiferous tubules. Testicular blood vessels express the erythroid glucose transporter protein and other markers, which are strongly expressed in brain blood vessels, and may contribute to the blood-testis barrier. This study was carried out to determine whether Sertoli cells or testicular
\end{abstract}

blood vessels express EBA. Tissues of other organs were used as controls for EBA expression. EBA was expressed by the endothelial cells in most microvessels of the testis, and in a few vessels of the epididymis, seminal vesicle, prostate gland, vas deferens and bladder-neck region. Furthermore, EBA was strongly and consistently detected in epithelial cells of the rete testis and dorsolateral prostate gland, and in a few epithelial cells of the ventral prostate gland, the seminal vesicle and the coagulating gland. However, Sertoli cells, which are the main site of the blood-testis barrier, were negative for EBA. In conclusion, EBA may have a wider role in rat tissues than has been previously appreciated.

\section{Introduction}

The endothelial barrier antigen (EBA) is a protein expressed selectively by the endothelial cells of the rat blood-brain barrier (Sternberger and Sternberger, 1987). EBA can be detected by immunostaining tissue sections and immunoblotting brain homogenate and microvessel preparations using a monoclonal antibody (anti-EBA) (Sternberger and Sternberger, 1987; Orte et al., 1999). Barrier vessels in the central nervous system (CNS) express EBA strongly (Sternberger and Sternberger, 1987; Sternberger et al., 1989; Perdiki et al., 1998; Ghabriel et al., 2000). Vessels of the optic nerve and retina, both of which develop as an extension from the CNS, also express EBA strongly (Sternberger and Sternberger, 1987; Lawrenson et al., $1995 a, b)$. In regions of the brain known to lack a blood-brain barrier, such as the area postrema, pineal gland, median eminence and choroid plexus, the antigen is absent or expressed weakly in only some endothelial cells (Sternberger and Sternberger, 1987; Rosenstein et al., 1992). In addition to endothelial cells of barrier vessels in the nervous system, EBA is also expressed by endothelial cells of vessels in a limited number of tissues, such as the pia mater (Sternberger and Sternberger, 1987; Rosenstein et al., 1992; Lawrenson et al., 1995a; Cassella et al., 1996, 1997). Blood vessels in the pia mater have barrier properties and

*Current address: Department of Medicine, School of Medicine, UCLA, CA, USA

Email:mounir.ghabriel@adelaide.edu.au many other similarities to CNS vessels (Allt and Lawrenson, 1997). Some endothelial cells in the spleen, and some cells in the epidermis tentatively identified as Langerhans' cells, were reported as reactive to anti-EBA (Sternberger and Sternberger, 1987). Blood vessels in liver, heart, adrenal gland, skeletal muscle, intestine, thymus, lymph nodes, pancreas, thyroid, skin and pituitary, which do not form blood-tissue barriers, do not express the antigen (Sternberger and Sternberger, 1987). The male reproductive system does not appear to have been investigated despite evidence for similarities between capillaries of the testis and brain (Holash et al., 1993; Stewart, 2000).

In the testis, there is both functional and structural evidence for a blood-testis barrier (see Setchell and Waites, 1975; Setchell, 1980, 2001). Much attention has been directed to the specialized junctions between pairs of adjacent Sertoli cells, which divide the cavity of the seminiferous tubule into basal and adluminal compartments (Dym and Fawcett, 1970). The diploid, mitotically dividing spermatogonia are located in the basal compartment and, during the leptotene stage of the first meiotic prophase, the spermatocytes move into the adluminal compartment, where the rest of the process of sperm formation occurs (Dym and Cavicchia, 1977; Russell, 1977). There is also some evidence that the peritubular myoid cells and endothelial cells of the testicular blood vessels contribute to the barrier function (Plöen and Setchell, 1992; Holash et al., 1993). As EBA has been described as a 'barrier

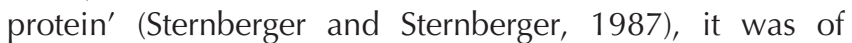
interest to determine whether the Sertoli cells, myoid cells 
(a)

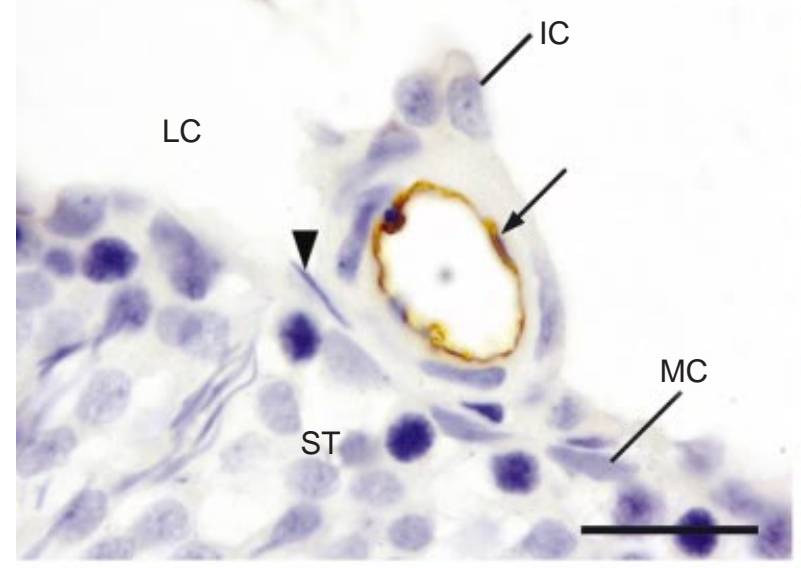

(c)

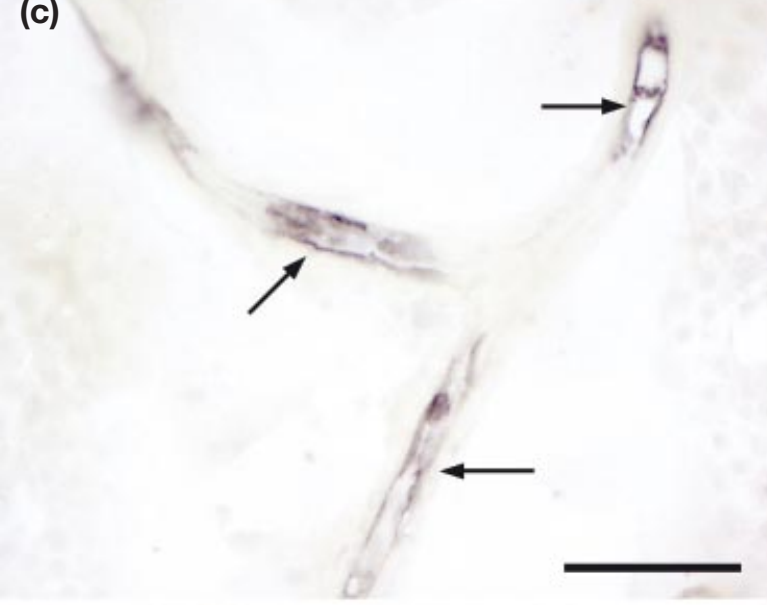

(e)

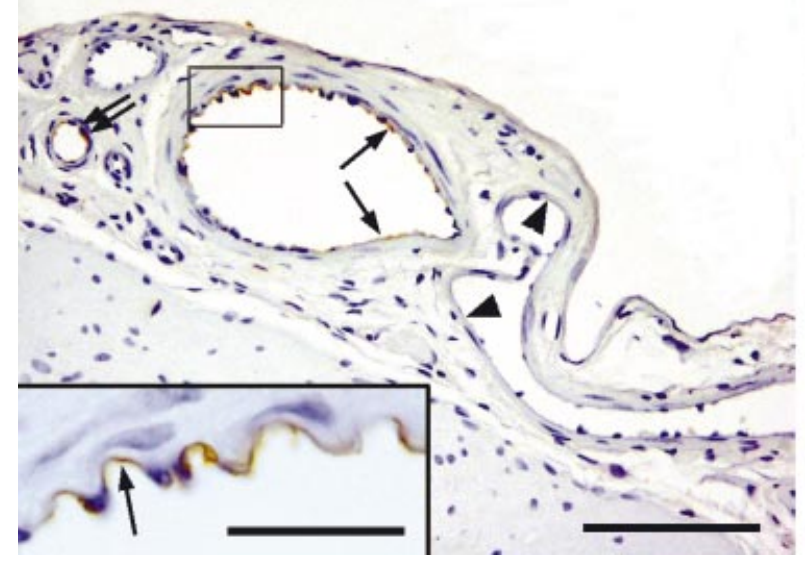

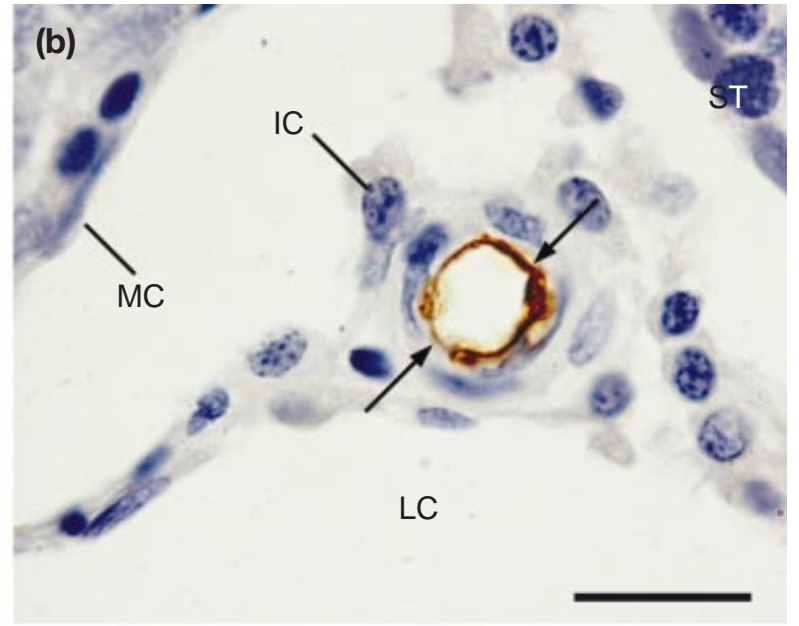

(d)
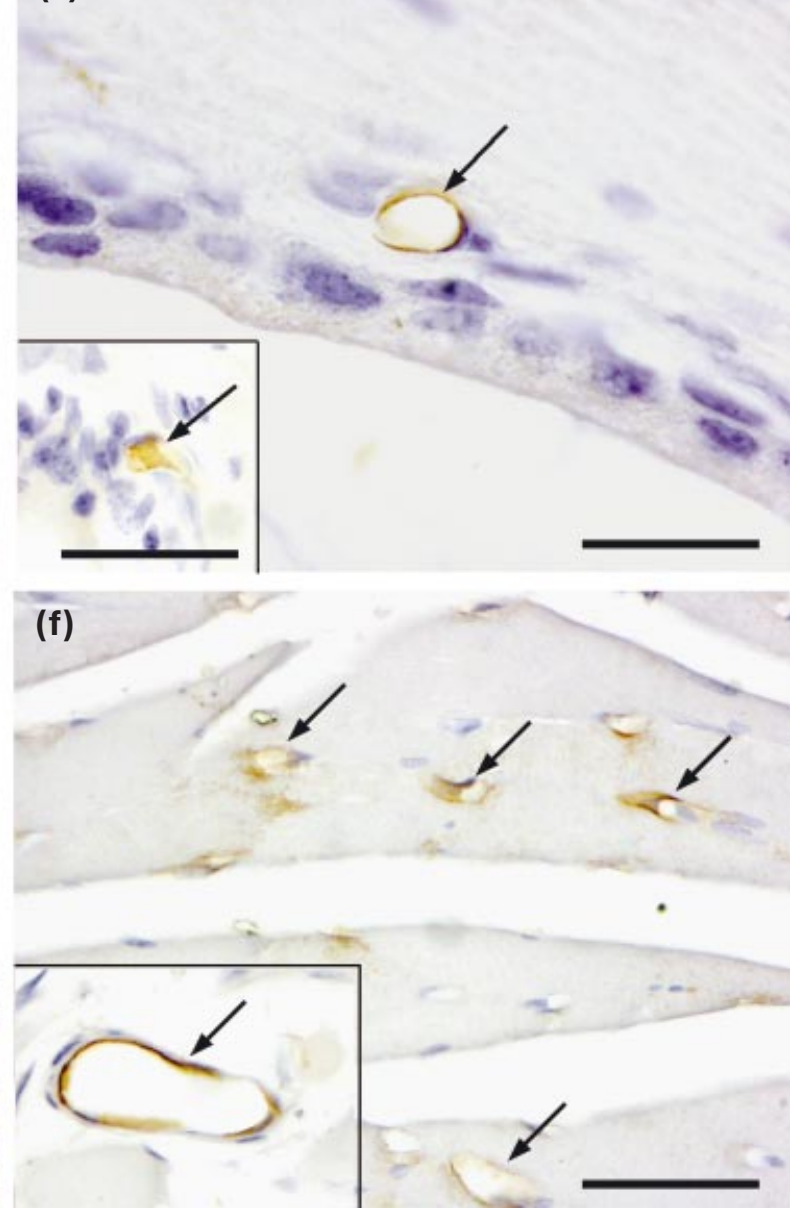

Fig. 1. Photomicrographs showing immunostaining for endothelial barrier antigen (EBA) in endothelial cells of microvessels in various tissues of the reproductive tract of the male rat. Positive immunolabelling appears as brown reaction product, except when nickel enhancement was used in which a black reaction product was seen (c). All figures are from sections counterstained with haematoxylin, except for (c). (a,b) Strong immunoreactivity in endothelial cells of interstitial testicular blood vessels (arrows). No labelling was seen in Sertoli and germinal epithelial cells in the seminiferous tubules (ST), interstitial cells (IC) and endothelial cells (arrowhead) of the wide lymphatic channels (LC) surrounding the seminiferous tubules or myoid cells (MC). (c) Nickel-enhanced immunostaining of interstitial vessels of the testis (arrows). (d) Immunostained endothelial cells of capillaries (arrows) located in the subepithelial connective tissues of the vas deferens. Epithelial cells lining the lumen do not show labelling for EBA. (e) Immunoreactivity is seen in endothelial cells lining the artery of the vas deferens (arrows) 
or endothelial cells of testicular blood vessels express this protein. In the present study, the distribution of EBA in the testis, epididymis, vas deferens, spermatic cord, seminal vesicle, coagulating gland, prostate gland, bulbourethral gland and urethra was investigated. The distribution of EBA in these tissues was compared with the expression of EBA in brain and spinal cord vessels as positive controls, and in other tissues known to lack EBA as negative controls.

\section{Materials and Methods}

\section{Animals, tissues and immunocytochemistry for EBA}

Five adult male Sprague-Dawley rats (350-430 g) were used under ethical approval. The rats were anaesthetized by i.p. injection of sodium pentobarbitone $\left(60 \mathrm{mg} \mathrm{kg}^{-1}\right)$. The circulation of the rats was flushed via the heart with PBS ( $\mathrm{pH} 7.4$, in an atmosphere of $95 \% \mathrm{O}_{2}$ and $5 \% \mathrm{CO}_{2}$ ) for $30 \mathrm{~s}$, and then with $4 \%(\mathrm{w} / \mathrm{v})$ paraformaldehyde fixative in $0.1 \mathrm{~mol}$ phosphate buffer $\mathrm{I}^{-1}, \mathrm{pH} 7.4$, under constant pressure of $100 \mathrm{~mm} \mathrm{Hg}$. The testis, epididymis, spermatic cord, seminal vesicles with the associated coagulating gland, ventral prostate gland, dorsolateral prostate gland, membranous urethra, bladder-neck region and bulbourethral gland were removed. The brain, spinal cord, suprarenal gland, liver, kidney, spleen, intestine, skin, skeletal muscle and heart were removed and used as control tissues for EBA expression. Tissues were immersed in $4 \%(\mathrm{w} / \mathrm{v})$ paraformaldehyde for $3 \mathrm{~h}$, processed in paraffin wax, cut into sections of $5 \mu \mathrm{m}$ and then mounted on slides coated with Silane (Sigma, St Louis, MO).

For the immunocytochemical detection of EBA, paraffin wax was removed from the tissue and endogenous peroxidase activity was blocked using $0.3 \%(\mathrm{v} / \mathrm{v}) \mathrm{H}_{2} \mathrm{O}_{2}$ in $70 \%(\mathrm{v} / \mathrm{v})$ methanol for $30 \mathrm{~min}$. After incubation for $1 \mathrm{~h}$ in $3 \%(\mathrm{v} / \mathrm{v})$ normal horse serum (NHS), the sections were incubated overnight in anti-EBA monoclonal primary antibody (SMI 71; Sternberger Monoclonals Inc., Lutherville, MD) at a dilution of $1: 3000$ in $1 \%(v / v)$ NHS. Sections were incubated in a biotinylated rat-adsorbed horse anti-mouse IgG secondary antibody (Vector Lab, Burlingame, CA) diluted 1:200 in 1\% $(\mathrm{v} / \mathrm{v})$ NHS followed by streptavidin-peroxidase conjugate (Rockland Inc., Gilbertsville, PA) at a dilution of 1:1000 in 1\% $(\mathrm{v} / \mathrm{v}) \mathrm{NHS}$. The peroxidase reaction product was developed by incubation for $10 \mathrm{~min}$ in 3,3'-diaminobenzidine tetrahydrochloride (DAB, $5 \mathrm{mg}$ in $10 \mathrm{ml}$ of $0.1 \mathrm{~mol} \mathrm{PBS} \mathrm{I}^{-1}$, and in $\left.30 \mu \mathrm{l} 3 \%(\mathrm{v} / \mathrm{v}) \mathrm{H}_{2} \mathrm{O}_{2}\right)$. On some slides, the glucose oxidase method was used for nickel enhancement of DAB (Shu et al., 1988). As a negative control for immunostaining, the primary antibody was omitted on some slides. Most slides were counterstained lightly with haematoxylin.

\section{Results}

\section{Tissue distribution of EBA}

Positive immunolabelling for EBA was detected in two types of cell: endothelial cells of microvessels and epithelial cells of some accessory organs of the male reproductive system.

Strong labelling for EBA was observed in endothelial cells of most microvessels of the testis, in the tunica albuginea, in the subcapsular tissues and in the interstitial compartment in all the animals examined (Fig. 1a-b). However, endothelial cells of lymphatic channels of the testis were not labelled (Fig. 1a). Endothelial cells of many microvessels in the wall of vas deferens were positive for EBA (Fig. $1 d$ ). Endothelial cells lining the artery and arterioles of the vas deferens also showed moderate immunoreactivity but large veins in the spermatic cord were not labelled (Fig. 1e). Many microvessels among the striated muscles (Fig. 1f) and the connective tissue surrounding the membranous urethra (Fig. 2a) showed moderate EBA labelling. A few microvessels in the seminal vesicle (Fig. 2b), epididymis (Fig. 2c), coagulating gland, ventral prostate gland (Fig. 2d) and dorsolateral prostate gland were labelled.

Labelling of epithelial cells was observed in the rete testis (Fig. 3a). The labelling was pronounced in the sector of rete testis tubules closest to the seminiferous tubules (Fig. 3a). Staining was not observed in the Sertoli cells or in any of the spermatogenic cells of the seminiferous tubules (Fig. 1a,b). Apart from endothelial cells of testicular blood vessels, other cells in the interstitial compartment of the testis and the peritubular myoid cells were EBA-negative (Fig. 1a,b). No consistent or reproducible staining was observed in epithelial cells of the epididymis or vas deferens. Examination of the accessory glands associated with the male reproductive system showed granular cytoplasmic staining for EBA. The epithelium of the dorsolateral prostate gland (Fig. 3b,c) showed strong and consistent labelling, especially in the acini next to the urethra, whereas cells in the stroma of the prostate gland were negative. The epithelium of the coagulating gland (Fig. $3 \mathrm{~d}$ ), the ventral prostate gland (Fig. 3e) and seminal vesicle (Fig. 3f) showed labelling in only a few epithelial cells in each tubular profile. No labelling was observed in the epithelium of the bulbourethral gland. All the positive labelling observed in cellular elements in the male reproductive tract was eliminated in control slides in which the primary antibody was omitted from the staining protocol (Fig. 4a). Control sections stained with haematoxylin and eosin for general histology did not show any similar brown deposits in epithelial or endothelial cells.

and in a smaller adjacent arteriole (double arrows), but not in the venous plexus of the spermatic cord (arrowheads). Inset shows enlargement of the area within the rectangle and shows labelling (arrow) of endothelial cells. (f) Moderate immunoreactivity is seen in most microvessels (arrows) among the striated muscles surrounding the membranous urethra. Scale bars represent (a,b,d) and inset in (e) $20 \mu \mathrm{m}$; $(\mathrm{c}, \mathrm{f})$ and inset in (d) $50 \mu \mathrm{m} ;(\mathrm{e}) 100 \mu \mathrm{m}$. 

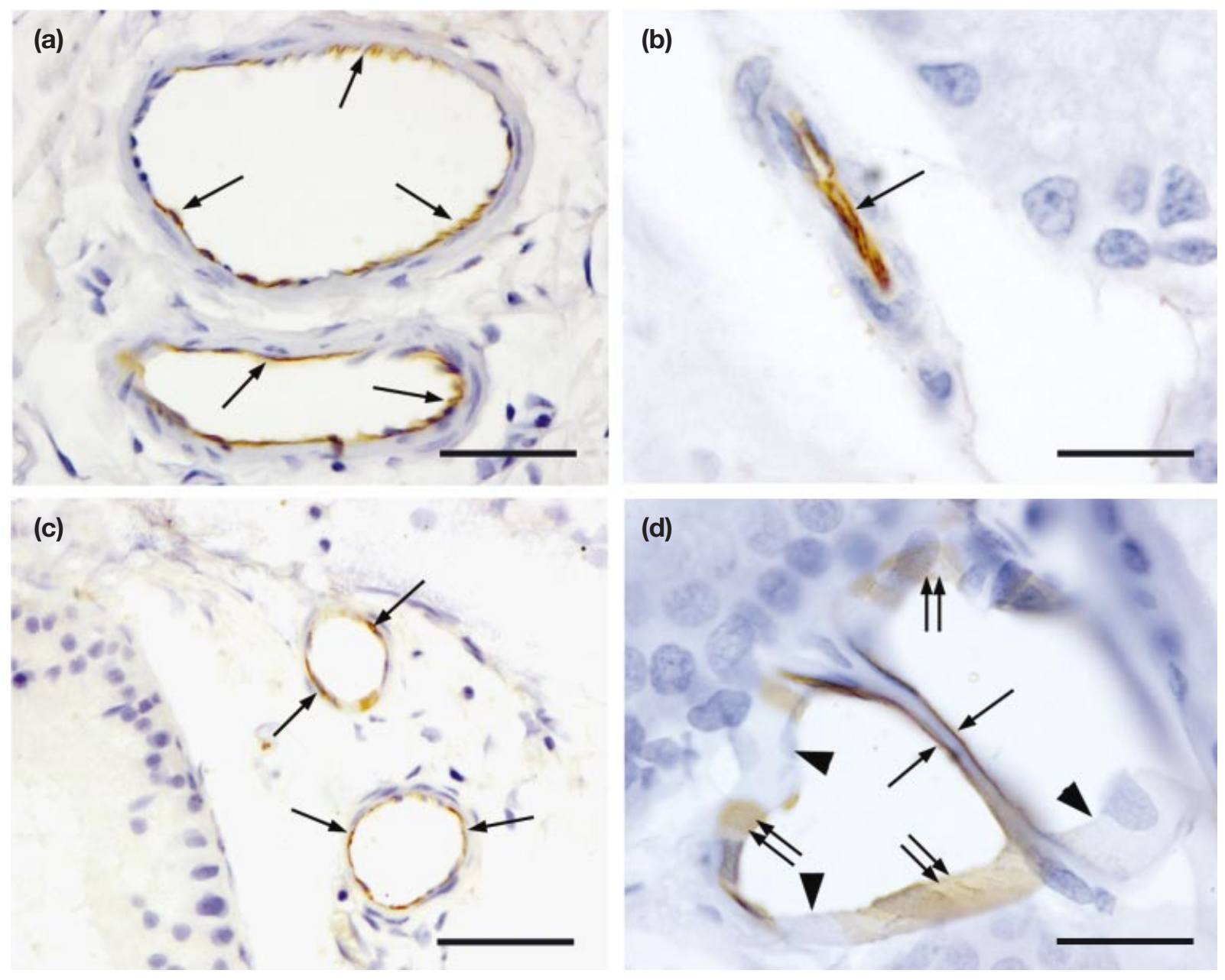

Fig. 2. Photomicrographs showing immunostaining for endothelial barrier antigen (EBA) in endothelial cells of microvessels in various tissues of the reproductive tract of the male rat. All figures are from sections counterstained with haematoxylin. (a) Immunostained endothelial cells (arrows) in blood vessels located in the connective tissue surrounding the membranous urethra. (b) EBA-positive microvessel (arrow) in the seminal vesicle, seen in an oblique section. The staining appears at the plane of endothelial cells. (c) EBA-positive vessels (arrows) in the head of the epididymis. (d) EBA-positive vessels (arrows) in the ventral prostate gland. Double arrows indicate EBA-positive regions of endothelial cells cut tangentially. Arrowheads indicate regions devoid of EBA staining, demonstrating regional variability in EBA expression in endothelial cells. Scale bars represent (a,c) $50 \mu \mathrm{m}$ and (b,d) $20 \mu \mathrm{m}$.

Examination of other tissues including the intestine (Fig. 4b), skin of the footpad, liver, kidney, adrenal cortex, skeletal muscle and cardiac muscle did not show any labelling for EBA. The brain and spinal cord (Fig. 4c) used as a positive control for EBA staining showed strong labelling of vessels throughout the grey and white matter. The spleen showed labelling of some endothelial cells of sinusoids in the red pulp (Fig. 4d). However, the central arterioles of the white pulp (Fig. 4d) and the splenic artery and vein at the hilum were not labelled. All the above findings were consistent in the five animals examined and were reproducible in several staining sessions.

\section{Discussion}

In the testis, there appears to be a barrier between the blood and the fluid in the lumina of the seminiferous tubules. Evidence for this barrier includes the uneven colouration of the testis after injection of certain dyes and the distribution of some radioactive markers determined by autoradiography or by comparing their volumes of distribution with morphological estimates of the volumes of the various compartments of the testis. There are also differences in composition between the blood plasma and testicular lymph, and the fluid in the lumina of the seminiferous 

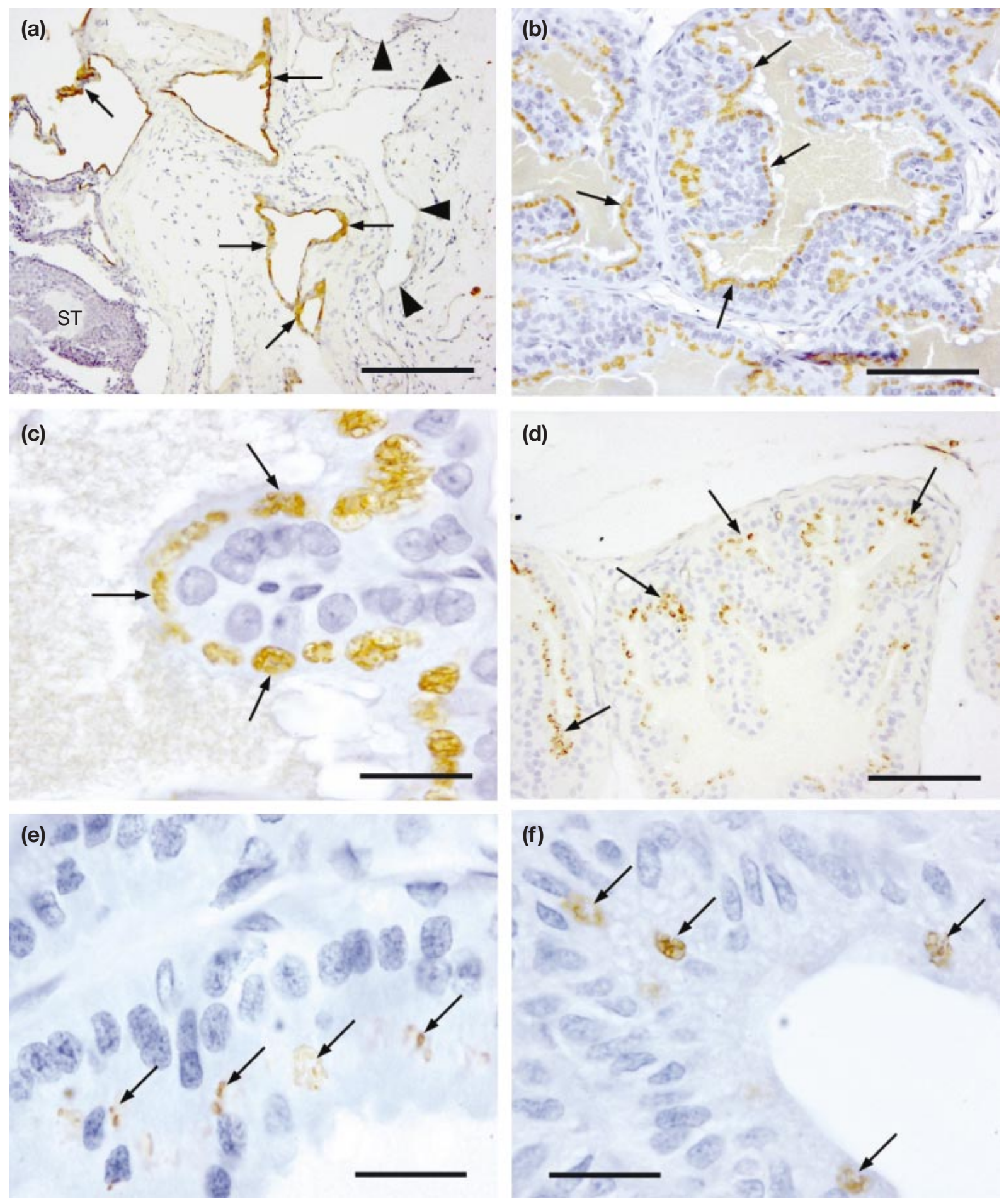

Fig. 3. Photomicrographs showing immunolabelling for endothelial barrier antigen (EBA) in epithelial cells of various tissues of the reproductive tract of the male rat. All sections were counterstained with haematoxylin. (a) EBA immunoreactivity was observed as a brown reaction product in the epithelium of the rete testis tubules (arrows) located close to the seminiferous tubules (ST), whereas rete testis profiles located further away are EBA-negative (arrowheads). (b-d) Positive labelling is seen in the cytoplasm of the (b,c) dorsolateral prostate gland and (d) coagulating gland. In the (e) ventral prostate gland and (f) seminal vesicle weak immunolabelling is seen in the cytoplasm of only a few cells (arrows). Scale bars represent (a) $200 \mu \mathrm{m}$, (b) $100 \mu \mathrm{m},(\mathrm{c}, \mathrm{e}, \mathrm{f}) 20 \mu \mathrm{m}$ and (d) $50 \mu \mathrm{m}$. 

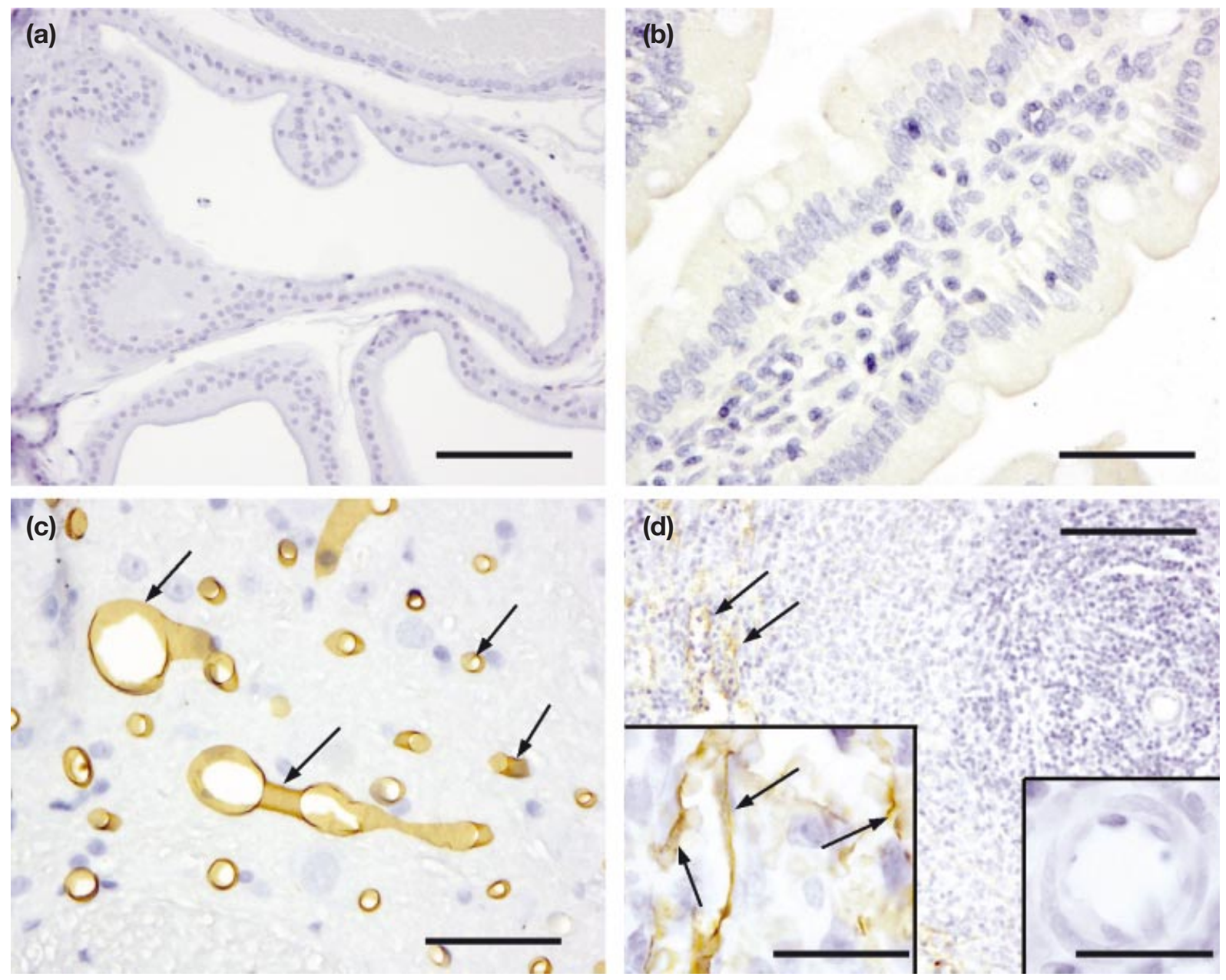

Fig. 4. Photomicrographs showing negative and positive control for endothelial barrier antigen (EBA) immunolabelling. All sections are counterstained with haematoxylin. (a) Dorsolateral prostate gland from a section in which the primary anti-EBA antibody was omitted in the staining protocol, as negative control, showing absence of immunoreactivity (compare with Fig. 3b,c). (b) A section from the small intestine immunostained for EBA but with the intestinal epithelium not showing any EBA labelling. The intestine was used as negative control tissue. (c) EBA-positive microvessels in the grey matter of the spinal cord (arrows). The spinal cord was used as positive control tissue for EBA labelling. (d) The red pulp of the spleen shows EBApositive endothelial cells (arrows) seen also at a higher magnification (left inset). The central arteriole of the white pulp (main figure and right inset) is not labelled. Scale bars represent (a,d) $100 \mu \mathrm{m},(\mathrm{b}, \mathrm{c}) 50 \mu \mathrm{m}$ and insets in (d) $20 \mu \mathrm{m}$.

tubules and the rete testis. In addition, various markers pass from the bloodstream into these testicular fluids at different rates (for reviews, see Setchell and Waites, 1975; Setchell, 1980; Setchell et al., 1994). Morphologically, attention has been focused on the specialized junctions between pairs of adjacent Sertoli cells in the tubules, which block the entry into the tubules of electron-opaque markers, such as lanthanum and horseradish peroxidase (Dym and Fawcett, 1970). In the present study, Sertoli cells did not show staining for EBA. In the brain, the barrier to the tracers is established in late gestation (Olsson et al., 1968) and EBA can be detected a few days after birth (Rosenstein et al., 1992; Cassella et al., 1996). EBA appears to play an important role in the blood-brain barrier, as injection of anti-EBA antibody causes opening of the blood-brain barrier (Ghabriel et al., 2000). The barrier function of Sertoli cells may be dependent on unknown regulatory factors, which are different from those that control barrier properties of brain endothelial cells. In the testis, the barrier to dyes and the specialized junctions between Sertoli cells develop only at puberty (Kormano, 1967; Russell et al., 1989), and the barrier becomes less effective outside the breeding season in seasonally breeding mammals. Although the barrier in the testis and spermatogenesis are both disrupted under some circumstances (vitamin A deficiency, disorganization of the microtubules in the Sertoli cell, after efferent duct ligation or injections of cadmium salts and in very old rats), spermatogenesis can be disrupted in other ways without the barrier being affected (for a review, see Setchell, 2001). 
In addition to the Sertoli cells, other cells in the testis, such as the endothelial cells of testicular blood vessels (Holash et al., 1993) and peritubular myoid cells (Fawcett et al., 1970), may also contribute to the barrier function. A partial barrier function of peritubular myoid cells was indicated from ultrastructural studies showing a clear peritubular space deep to the myoid cells in contrast to the interstitial tissue, which showed proteinaceous content. These cells are also able to exclude large molecular tracers, such as thorium dioxide and carbon, but allow entry of smaller tracers, such as ferritin and peroxidase (Fawcett et al., 1970). The peritubular myoid cells are joined by tight junctions, although 10-15\% of the junctions appear to have gaps of $20 \mathrm{~nm}$ (Dym and Fawcett, 1970). These myoid cells also contain a specific transport system for urea (Fenton et al., 2000). However, in the present study no staining for EBA was noted in the peritubular myoid cells.

Endothelial cells of testicular microvessels share several features with those in the brain. There is a specific saturable transport system for leucine in endothelial cells of the testis and the kinetic properties of this system are very similar to those found in the brain (Bustamante and Setchell, 2000). Endothelial cells in the testis contain the glucose transporter GLUT-1, gamma glutamyl transpeptidase and the multidrug resistance gene product P-glycoprotein (Harik et al., 1990; Holash et al., 1993), which was thought to be specific to the brain. Testicular expression of EBA, as observed in the present study, provides further support for the similarities between brain and testicular blood vessels. It has also been demonstrated that the Leydig cells, which lie close to the endothelial cells in the testis, contain S-100 protein, the glial fibrillary acidic protein and glutamine synthetase (Holash et al., 1993). These are characteristic markers of astrocytes, the cells in the brain that may confer the barrier properties on brain endothelial cells (Risau, 1991).

Although the results discussed above indicate that testicular blood vessels share many biochemical markers with brain vessels, there are some differences. Unlike brain vessels, those of the testis do not express the transferrin receptor (Holash et al., 1993). Although endothelial cells of the brain and testis express the P-glycoprotein, the distribution of this marker is different in the two systems. Pglycoprotein is localized to luminal membranes in brain endothelial cells but to luminal and abluminal membranes in testicular endothelial cells (Stewart et al., 1996). The biological significance of the difference in the distribution of P-glycoprotein in the two systems is not understood (Stewart et al., 1996). In addition, morphological and physiological studies showed some differences between the two vascular beds. Albumin, which does not freely enter the brain, is readily detectable in the testicular lymph (for a review, see Setchell and Waites, 1975). Testicular capillaries are continuous and have intercellular tight junctions (Weihe et al., 1979), but the density of these junctions is lower than that of brain endothelial cells (Holash et al., 1993; Stewart, 2000). Testicular capillaries are larger and have a thicker wall and a higher density of mitochondria than that of brain capillaries (Holash et al., 1993; Stewart, 2000). Other studies have provided evidence for leakage of Evans blue (Caster et al., 1955) and trypan blue (Kormano, 1968) into the interstitial tissues of the testis. Horseradish peroxidase can also enter the interstitial tissues of the testis (Weihe et al., 1979), but cannot enter the brain (Brightman and Reese, 1969). The difference in permeability between testicular and brain blood vessels may be due to differences in the structure and function of the tight junctions between endothelial cells in the two systems. Brain blood vessels have long sinuous intercellular junctions with high electrical resistance. Testicular blood vessels have wide compartments between the series of tight junctional appositions and some intercellular junctions are expanded (> $10 \mathrm{~nm}$ ), indicating patent junctions (Fawcett et al., 1970; Holash et al., 1993; Stewart, 2000). Fifteen per cent of testicular blood vessels have wide junctions with a higher cleft index (Holash et al., 1993), which may explain their higher permeability compared with brain vessels. Nevertheless, in the present study, strong EBA labelling was observed in the majority of testicular vessels.

In the current study, strong and consistent labelling with anti-EBA was observed in the epithelium of the dorsolateral prostate gland, and in a few epithelial cells of the coagulating gland, the ventral prostate gland and the seminal vesicles. It is possible that anti-EBA may be crossreacting with tissue components or labelling a related protein. However, high specificity of anti-EBA (Sternberger and Sternberger, 1987) makes this unlikely. The prostatic epithelium has tight junctions and barrier properties (Kachar and Reese, 1983). However, it is unlikely that EBA expression is directly related to the tight junctions in prostatic epithelium as: (i) it is not expressed in epithelia with tight junctions in other body organs; and (ii) in brain endothelial cells, EBA is not associated with intercellular junctions, but is expressed on the luminal membrane (Rosenstein et al., 1992; Lawrenson et al., 1995a; Zhu et al., 2001). In the prostate, EBA was present predominantly in the apical cytoplasm, which suggests its secretion into the fluids of associated glands. Thus, EBA in this accessory gland may have an unknown function in relation to survival or motility of spermatozoa. The secretions of the male reproductive accessory glands vary widely in function and chemical composition in different species (for a review, see Setchell et al., 1994). In rats, diversity in chemical composition occurs among the secretions of the various reproductive accessory glands. The prostatic secretion contains inositol, polyamines and epidermal growth factor (Jacobs and Story, 1988). A 22 kDa protein has also been detected in the rat ventral prostate gland (Carmo-Fonseca and Vaz, 1989). Anti-EBA reacts with immunoblots of rat brain microvessel membranes and shows three positive bands of 30, 25 and $23.5 \mathrm{kDa}$ proteins (Sternberger and Sternberger, 1987). Whether the $22 \mathrm{kDa}$ prostatic protein is related to the $23.5 \mathrm{kDa}$ band of brain preparations is yet to be determined. However, immunofluorescence showed that the $22 \mathrm{kDa}$ protein is expressed only in the ventral prostate gland and not in the dorsolateral 
prostate gland (Carmo-Fonseca and Vaz, 1989), which in the present study showed the strongest immunoreactivity to anti-EBA, whereas only a few epithelial cells were positive for EBA in the ventral prostate gland. Preliminary observations in our laboratory using PAGE and immunoblotting indicate that proteins of similar molecular masses in the brain, testis and prostate gland are reacting with anti-EBA.

In the current study, epithelial cells of the coagulating gland also showed labelling for EBA. The coagulating gland is considered as the anterior lobe of the prostate gland, although anatomically it is closely apposed to the seminal vesicle. Its secretion may have a similar function to that of the main prostate gland. However, the presence of only a few EBA-positive cells in the seminal vesicle may reflect a difference in function between the fluids secreted by the seminal vesicle and the coagulating gland. Seminal vesicle fluid contains a substrate (SVSII) for enzymes secreted by the coagulating gland to form the copulatory plug (Setchell et al., 1994). Seminal vesicle proteins bind to sperm membrane, and may have an effect on the spermatozoa while the binding is regulated by other proteins in the ejaculate secreted by the coagulating gland (Carballada and Esponda, 1998). EBA labelling of the rete testis epithelium reported in the current study may also be related to a specific unknown function of the luminal fluid.

The authors would like to thank N. Gagliardi for expert assistance. J. J. Lu is supported by an Adelaide University Grant and is a holder of an International Postgraduate Research Scholarship.

\section{References}

Allt G and Lawrenson JG (1997) Is the pial microvessel a good model for blood-brain barrier studies? Brain Research Reviews 24 67-76

Brightman MB and Reese TS (1969) Junctions between intimately apposed cell membranes in the vertebrate brain Journal of Cell Biology $\mathbf{4 0}$ 648-677

Bustamante JC and Setchell BP (2000) The uptake of amino acids, in particular leucine, by isolated perfused testes of rats Journal of Andrology 21 452-463

Carballada R and Esponda P (1998) Binding of seminal vesicle proteins to the plasma membrane of rat spermatozoa in vivo and in vitro. International Journal of Andrology 21 19-28

Carmo-Fonseca M and Vaz Y (1989) Immunocytochemical localisation and lectin-binding properties of the $22 \mathrm{kDa}$ secretory protein from rat ventral prostate Biology of Reproduction 40 153-164

Cassella JP, Lawrenson JG, Allt G and Firth JA (1996) Ontogeny of four blood-brain barrier markers: an immunocytochemical comparison of pial and cerebral cortical microvessels Journal of Anatomy 189 407-415

Cassella JP, Lawrenson JG, Lawrence L and Firth JA (1997) Differential distribution of an endothelial barrier antigen between the pial and cortical microvessels of the rat Brain Research 744 335-338

Caster WO, Simon AB and Armstrong WD (1955) Evans blue space in tissues of the rat American Journal of Physiology 183 317-321

Dym M and Cavicchia JC (1977) Further observations on the blood-testis barrier in monkeys Biology of Reproduction 17 390-403

Dym M and Fawcett DW (1970) The blood-testis barrier in the rat and the physiological compartmentation of the seminiferous epithelium Biology of Reproduction 3 308-326

Fawcett DW, Leak LV and Heidger PM (1970) Electron microscopic observations on the structural components of the blood-testis barrier Journal of Reproduction and Fertility Supplement 10 105-122

Fenton RA, Howorth A, Cooper GJ, Meccariello R and Morris ID (2000)
Molecular characterization of a novel UT-A urea transporter isoform (UT-A5) in testis American Journal of Physiology 279 C1425-C1431

Ghabriel MN, Zhu C, Hermanis G and Allt G (2000) Immunological targeting of the endothelial barrier antigen (EBA) in vivo leads to opening of the blood-brain barrier Brain Research 878 127-135

Harik SI, Kalaria RN, Andersson L, Lundahl P and Perry G (1990) Immunocytochemical localization of the erythroid glucose transporter: abundance in tissues with barrier functions Journal of Neurosciences $\mathbf{1 0}$ 3862-3872

Holash JA, Harik SI, Perry G and Stewart PA (1993) Barrier properties of testis microvessels Proceedings National Academy of Sciences USA 90 $11069-11073$

Jacobs SC and Story MT (1988) Exocrine secretion of epidermal growth factor by the rat prostate: effect of adrenergic agents, cholinergic agents and vasoactive intestinal peptide Prostate 13 79-87

Kachar B and Reese TS (1983) Formation of misplaced and reflexive tight junction strands in prostate epithelial cells Journal of Ultrastructural Research 82 90-95

Kormano M (1967) Dye permeability and alkaline phosphatase activity of testicular capillaries in the postnatal rat Histochemie $9327-338$

Kormano M (1968) Penetration of intravenous trypan blue into the rat testis and epididymis Acta Histochemica 30 133-136

Lawrenson JG, Ghabriel MN, Reid AR, Gajree TN and Allt G (1995a) Differential expression of an endothelial barrier antigen between the CNS and the PNS Journal of Anatomy 186 217-221

Lawrenson JG, Ghabriel MN, Reid AR, Gajree TN and Allt G (1995b) Distribution of a putative endothelial barrier antigen in the ocular and orbital tissues of the rat British Journal of Ophthalmology 79 462-466

Olsson Y, Klatzo I, Sourander P and Steinwall O (1968) Blood-brain barrier to albumin in embryonic new born and adult rats Acta Neuropathologica $10117-122$

Orte C, Lawrenson JG, Finn TM, Reid AR and Allt G (1999) A comparison of blood-brain barrier and blood-nerve barrier endothelial cell markers Anatomy and Embryology 199 509-517

Perdiki M, Farooque M, Holtz A, Li GL and Olsson Y (1998) Expression of endothelial barrier antigen immunoreactivity in blood vessels following compression trauma to rat spinal cord. Temporal evolution and relation to the degree of the impact Acta Neuropathologica 96 8-12

Plöen L and Setchell BP (1992) Blood-testis barriers revisited International Journal of Andrology 15 1-4

Risau W (1991) Induction of blood-brain barrier endothelial cell differentiation Annals of the New York Academy of Sciences 633 405-419

Rosenstein JM, Krum JM, Sternberger LA, Pulley MT and Sternberger NH (1992) Immunocytochemical expression of the endothelial barrier antigen (EBA) during brain angiogenesis Developmental Brain Research 66 47-54

Russell L (1977) Movement of spermatocytes from the basal to the adluminal compartment of the rat testis American Journal of Anatomy $148313-328$

Russell LD, Bartke A and Goh JC (1989) Postnatal development of the Sertoli cell barrier, tubular lumen and cytoskeleton of Sertoli and myoid cells in the rat, and their relationship to tubular fluid secretion and flow American Journal of Anatomy 184 179-189

Setchell BP (1980) The functional significance of the blood-testis barrier Journal of Andrology $13-10$

Setchell BP (2001) La barriere sang-testicule Andrologie 11 15-20

Setchell BP and Waites GMH (1975) The blood-testis barrier. In Handbook of Physiology, Section 7, Endocrinology Volume V Male Reproductive System pp 143-172 Eds RO Greep and EB Astwood. American Physiological Society, Washington DC

Setchell BP, Maddocks S and Brooks DE (1994) Anatomy, vasculature, innervation and fluids of the male reproductive tract. In The Physiology of Reproduction 2nd Edn pp 1063-1175 Eds E Knobil and JD Neill. Raven Press, New York

Shu S, Ju G and Fan L (1988) The glucose oxidase-DAB-nickel method in peroxidase histochemistry of the nervous system Neuroscience Letters 85 169-171

Sternberger NH and Sternberger LA (1987) Blood-brain barrier protein recognized by monoclonal antibody Proceedings National Academy of Sciences USA 84 8169-8173 
Sternberger NH, Sternberger LA, Kies MW and Shear CR (1989) Cell surface endothelial proteins altered in experimental allergic encephalomyelitis Journal of Neuroimmunology 21 241-248

Stewart PA (2000) Endothelial vesicles in the blood-brain barrier: are they related to permeability? Cellular and Molecular Neurobiology 20 149-163

Stewart PA, Béliveau R and Rogers KA (1996) Cellular localization of $P$-glycoprotein in brain versus gonadal capillaries Journal of Histochemistry and Cytochemistry 44 679-685

Weihe E, Nimmrich H, Metz J and Forssmann WG (1979) Horseradish peroxidase as a tracer for capillary permeability studies Journal of Histochemistry and Cytochemistry 27 1357-1359
Zhu C, Ghabriel MN, Blumbergs PC, Reilly PL, Manavis J, Youssef J, Hatami S and Finnie JW (2001) Clostridium perfringens prototoxininduced alteration of endothelial barrier antigen (EBA) immunoreactivity at the blood-brain barrier (BBB) Experimental Neurology 169 72-82

Received 30 July 2001.

First decision 1 October 2001

Revised manuscript received 27 October 2001.

Accepted 29 October 2001. 